Atmos. Chem. Phys., 13, 9855-9867, 2013

www.atmos-chem-phys.net/13/9855/2013/

doi:10.5194/acp-13-9855-2013

(c) Author(s) 2013. CC Attribution 3.0 License.

\title{
Microphysical process rates and global aerosol-cloud interactions
}

\author{
A. Gettelman ${ }^{1}$, H. Morrison ${ }^{1}$, C. R. Terai ${ }^{2}$, and R. Wood $^{2}$ \\ ${ }^{1}$ National Center for Atmospheric Research, 1850 Table Mesa Dr., Boulder, CO 80305, USA \\ ${ }^{2}$ Department of Atmospheric Sciences, Box 351640, University of Washington, Seattle, WA 98195, USA
}

Correspondence to: A. Gettelman (andrew@ucar.edu)

Received: 12 April 2013 - Published in Atmos. Chem. Phys. Discuss.: 3 May 2013

Revised: 19 August 2013 - Accepted: 30 August 2013 - Published: 7 October 2013

\begin{abstract}
Cloud microphysical process rates control the amount of condensed water in clouds and impact the susceptibility of precipitation to cloud-drop number and aerosols. The relative importance of different microphysical processes in a climate model is analyzed, and the autoconversion and accretion processes are found to be critical to the condensate budget in most regions. A simple steady-state model of warm rain formation is used to illustrate that the diagnostic rain formulations typical of climate models may result in excessive contributions from autoconversion, compared to observations and large eddy simulation models with explicit bin-resolved microphysics and rain formation processes. The behavior does not appear to be caused by the bulk process rate formulations themselves, because the steady-state model with the same bulk accretion and autoconversion has reduced contributions from autoconversion. Sensitivity tests are conducted to analyze how perturbations to the precipitation microphysics for stratiform clouds impact process rates, precipitation susceptibility and aerosol-cloud interactions (ACI). With similar liquid water path, corrections for the diagnostic rain assumptions in the GCM based on the steady-state model to boost accretion indicate that the radiative effects of ACI may decrease by $20 \%$ in the GCM. Links between process rates, susceptibility and ACI are not always clear in the GCM. Better representation of the precipitation process, for example by prognosticating precipitation mass and number, may help better constrain these effects in global models with bulk microphysics schemes.
\end{abstract}

\section{Introduction}

Aerosols have many direct, semi-direct and indirect effects on clouds. The indirect effects, or aerosol-cloud Interactions (ACI), result from more cloud condensation nuclei $(\mathrm{CCN})$ creating a population of more and smaller particles for a given amount of cloud water. This makes the clouds brighter (first indirect effect, Twomey, 1977), as well as affecting the resulting lifetime of the clouds in complex ways (second indirect or lifetime effect Albrecht, 1989). The effects on cloud lifetime are complex, and depend upon precipitation processes in clouds. We will focus in this paper on stratiform clouds. Convective clouds with strong vertical motions, create their own complex challenges in understanding aerosol effects (Rosenfeld et al., 2008).

Many global models of the atmosphere (General Circulation Models or GCMs) have started to treat aerosol indirect effects (e.g., Boucher and Lohmann, 1995; Quaas et al., 2008). The resulting global effects of aerosols on radiative fluxes appear larger than many observational estimates from satellites (Quaas et al., 2008) or inverse methods (Murphy et al., 2009). However, Penner et al. (2011) suggest that the drop number concentration - aerosol optical depth relationship ( $\left.\operatorname{dn} N_{\mathrm{d}} / \mathrm{d} \ln \mathrm{AOD}\right)$ from present-day observations used by Quaas et al. (2008) may underestimate aerosol effects. If simulated effects are too large, satellite studies and more detailed models indicate that a likely culprit is too large a change in liquid water path (LWP) with the changing drop number induced by aerosols, resulting in too large a radiative effect (e.g., Wang et al., 2012). The formation of precipitation, as a primary sink for liquid water, is critical in this process. Also important are entrainment processes (e.g., Ackerman et al., 2004; Guo et al., 2011) that can dry clouds by increased entrainment of overlying air. 
The evolution of precipitation in clouds is affected by aerosols through their impact on the droplet size distribution. Increases in aerosol are seen to increase cloud-drop number (Martin et al., 1994; Ramanathan et al., 2001). Increased drop number means smaller mean drop size for constant LWP. The result is smaller drops that do not coalesce and grow into precipitation as easily. This coalescence process (described by the stochastic collection equation) is too detailed to completely represent in bulk formulations of cloud-drop size distributions. Thus, the coalescence process of precipitation formation is often represented by a parameterization of the autoconversion of cloud liquid to precipitation, while the collection process of cloud droplets onto existing raindrops is represented by an accretion process. Most current GCMs assume a diagnostic treatment of precipitation whereby time tendencies of precipitation are set to zero and precipitation is obtained by a vertical integration of microphysical process rates. On the other hand, Posselt and Lohmann (2008) assumed a prognostic treatment of precipitation that allowed precipitation mass to persist in the atmosphere across time steps in the ECHAM GCM, and found that it shifted rain production towards accretion. Wood (2005) note that autoconversion should play a minor role in increasing drizzle water content.

Autoconversion and accretion rates are affected by changes in drop number. Autoconversion is sensitive to drop number (Khairoutdinov and Kogan, 2000) while accretion rates are nearly independent of the drop number: they are only affected via the mass of condensate undergoing autoconversion. If accretion dominates over autoconversion for shallow (Stevens and Seifert, 2008) and stratocumulus (Wood, 2005) clouds, this would tend to dampen the ACI: reducing the role of autoconversion, which depends on clouddrop number, reduces the effect of aerosols on cloud radiative properties (Wood et al., 2009). Consistent with this idea, the change in rain rate with respect to aerosols or drop number (called the "susceptibility" of precipitation to aerosols following Feingold and Siebert, 2009) seems to decrease at higher LWPs where accretion dominates (Jiang et al., 2010; Terai et al., 2012). Complicating diagnosis however, Golaz et al. (2011) found a strong co-variance between ACI and LWP with changes in process rates to achieve radiative balance in a GCM.

In contrast to previous work on microphysics processes in GCMs (Posselt and Lohmann, 2008; Wang et al., 2012), we compare GCM process rates to rates derived from in situ observations and we explore a simple steady-state model of microphysical processes. We first examine microphysical process rates in a GCM (Sect. 2). The analysis focuses on a single GCM but the parameterization of microphysical processes is similar to many global models. We analyze a simple steady-state model (Sect. 3) to understand interactions of process rates and susceptibility of precipitation to changes in drop number. We compare the GCM to the simple model and observations in Sect. 4. We then use different formulations of the GCM microphysics to better understand the sensitivity of the GCM cloud aerosol interactions in Sect. 5. Discussion and Conclusions are in Sect. 6.

\section{Balance of processes in a GCM}

\subsection{Model description}

The GCM we use in this study is the National Center for Atmospheric Research (NCAR) Community Atmosphere Model version 5.2 (CAM5). CAM5 includes an advanced physical parameterization suite (Gettelman et al., 2010; Neale et al., 2010) that is well suited for understanding aerosol indirect effects in stratiform clouds. CAM5 cloud microphysics is typical to many other GCMs. CAM5 has a 2-moment cloud microphysics scheme (Morrison and Gettelman, 2008; Gettelman et al., 2008), coupled to a modal aerosol model with 3 modes (Liu et al., 2012). CAM5 aerosols affect activation of stratiform cloud droplets and ice crystals. Aerosols in the standard version of CAM5 do not interact with convective cloud drops and ice crystals. A separate scheme is used to describe convective clouds and convective microphysics (Zhang and McFarlane, 1995). CAM5 has a consistent treatment of the radiative effects of cloud droplets and ice crystals, and radiatively active snow (see Gettelman et al., 2010 for details). We will also perform several sensitivity tests as noted below (see Sect. 5) with different CAM5 formulations.

In CAM, liquid autoconversion (auto) and accretion (accr) are defined following Khairoutdinov and Kogan (2000):

$$
\begin{aligned}
& \frac{\partial q_{\mathrm{r}}}{\partial t}{ }_{\text {auto }}=A_{\mathrm{u}}=1350 q_{\mathrm{c}}^{2.47} N_{\mathrm{d}}^{-1.79} \\
& \frac{\partial q_{\mathrm{r}}}{\partial t}{ }_{\text {accr }}=A_{\mathrm{c}}=67\left(q_{\mathrm{c}} q_{\mathrm{r}}\right)^{1.15} .
\end{aligned}
$$

Autoconversion depends on cloud water $\left(q_{\mathrm{c}}\right)$ and inversely on cloud-drop number $\left(N_{\mathrm{d}}\right)$ so that increases in drop number decrease rain mixing ratio $\left(q_{\mathrm{r}}\right)$ to a first approximation, leading to more liquid in the presence of higher number (more aerosols). Accretion depends only on $q_{\mathrm{c}}$ and $q_{\mathrm{r}}$. The rain mixing ratio $q_{\mathrm{r}}$ in CAM is diagnostic. It is determined by partitioning the total amount of liquid into cloud water and rain water, and the rain water is removed as a surface flux in the current time step.

To isolate cloud lifetime and precipitation effects of aerosols in a GCM, first we examine the key CAM microphysical process rates in Fig. 1. This analysis treats evaporation and condensation as large-scale (macro-physical) quantities, and here we focus only on the microphysics. These terms are important in the overall amount of cloud water. We look at the storm track regions, where LWP is large, and in CAM there is a large sensitivity of cloud feedbacks in this region (Gettelman et al., 2012). Over the storm track regions 

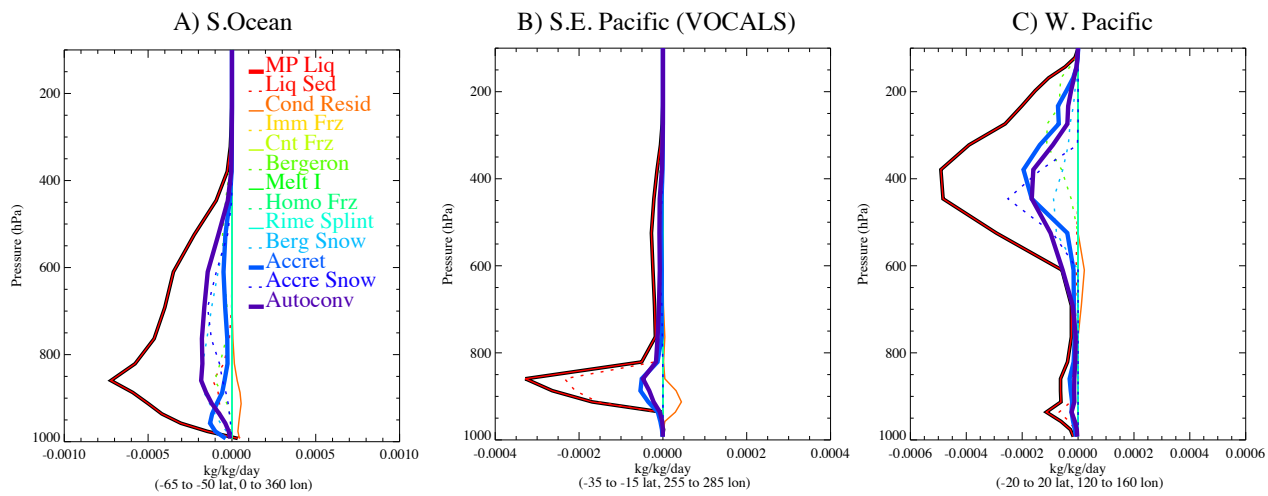

Fig. 1. Profiles of annual average grid mean liquid microphysical process rates (colored solid and dotted lines) in CAM5. (A) Southern Ocean ( -65 to 50 lat, all longitudes), (B) southeast Pacific $\left(-35\right.$ to $-15^{\circ} \mathrm{S}$ and $255-285^{\circ} \mathrm{E}$ ) and (C) tropical western Pacific (TWP: $20^{\circ} \mathrm{S}$ to $20^{\circ} \mathrm{N}$ and $120-160^{\circ}$ E). Processes are the total microphysical tendency (MP Liq), Sedimentation (Liq Sed) and the residual condensation to remove supersaturation (Cond Sed), immersion freezing (ImmFrz), contact freezing (Cnt Frz), the Bergeron vapor deposition process (Bergeron), melting of ice (Melt I), rime splintering (Rime Splint), homogeneous freezing of cloud drops to ice (Homo Frz), autoconversion (Autoconv), accretion (Accret) and the vapor deposition onto snow (Berg Snow).

(S. Hemisphere shown in Fig. 1a), autoconversion of liquid to precipitation, accretion of liquid by snow and the transition from liquid to ice (Bergeron process) are the largest sink terms for liquid. Autoconversion is the largest process rate from $500-900 \mathrm{hPa}$, with the Bergeron vapor deposition larger at lower pressures. Accretion is lower than autoconversion. In the southeast Pacific off the coast of S. America (Fig. 1b), there is a large liquid sedimentation term, that slowly settles condensate converted by large-scale condensation, but the dominant microphysical processes after that are accretion and autoconversion. There is slightly more autoconversion near cloud top $(\sim 800 \mathrm{hPa})$. Over the tropical western Pacific $\left(20^{\circ} \mathrm{S}\right.$ to $20^{\circ} \mathrm{N}$ and $120-160$ longitude), the dominant processes are similar. Autoconversion and accretion onto both rain and snow are the dominant sink terms for cloud liquid (Fig. 1c). Liquid is present down to about $-30^{\circ} \mathrm{C}$ in small amounts due to convective detrainment (Neale et al., 2010). Several other terms are important due to ice processes at high altitudes (homogeneous freezing and accretion of liquid onto snow). Accretion and autoconversion have similar magnitudes. Figure 1 shows that regardless of the cloud regime or region, accretion and autoconversion largely determine the sink of cloud liquid water.

\section{Steady-state model}

Given the dominance of the autoconversion and accretion processes, we explore a simple model that represents these essential features in much the same way as the GCM. We use the steady-state model of Wood et al. (2009), which captures many of the qualitative and quantitative features of warm rain processes. Time tendencies of precipitation mass (and number) mixing ratios are explicitly calculated and precipitation quantities are prognosed across time steps. The model calculates an equilibrium state for rain rate, rain number and cloud water concentration given an input cloud height, replenishment rate and cloud-drop number concentration. The essential processes are autoconversion and accretion, combined with sedimentation and removal of cloud water. The model treats rain prognostically, and uses autoconversion from Khairoutdinov and Kogan (2000) as in Eq. (1). We use the accretion calculation of Khairoutdinov and Kogan (2000) as in Eq. (2), to be consistent with the GCM simulations, and keep all other parameters the same. Following Wood et al. (2009) the liquid lapse rate is $2 \times 10^{-6} \mathrm{~kg} \mathrm{~m}^{-4}$, the replenishment timescale is $1 \mathrm{~h}$ and drizzle drop embryos are assumed to have a radius of 22 microns. Cloud height varies from $25-2500 \mathrm{~m}$ to alter the LWP and the drop number concentration is varied from $10-1000 \mathrm{~cm}^{-3}$. The standard case, seen in black in Fig. 2, reproduces the sensitivity of precipitation to LWP and $N_{\mathrm{d}}$ in Wood et al. (2009), their Fig. 1 b.

We then explore several other cases, altering the steadystate model to try to replicate how the bulk microphysics in the GCM operates. These cases are described below and in Table 1. The bulk microphysics in the GCM differs in several important respects from this steady-state model. Case Qcv=2 modifies the process rates assuming small scale variability of cloud water as in the GCM, and the DiagQr cases alter accretion analogous to how the GCM treats rain. Figures 2 and 3 present steady-state results. Individual points in Fig. 3 are from the height (LWP) and drop number phase space.

\subsection{Small-scale variability}

As described by Morrison and Gettelman (2008), the bulk microphysics treats the impact of the sub-grid variability of cloud water-mass mixing ratio in a grid box, by assum- 

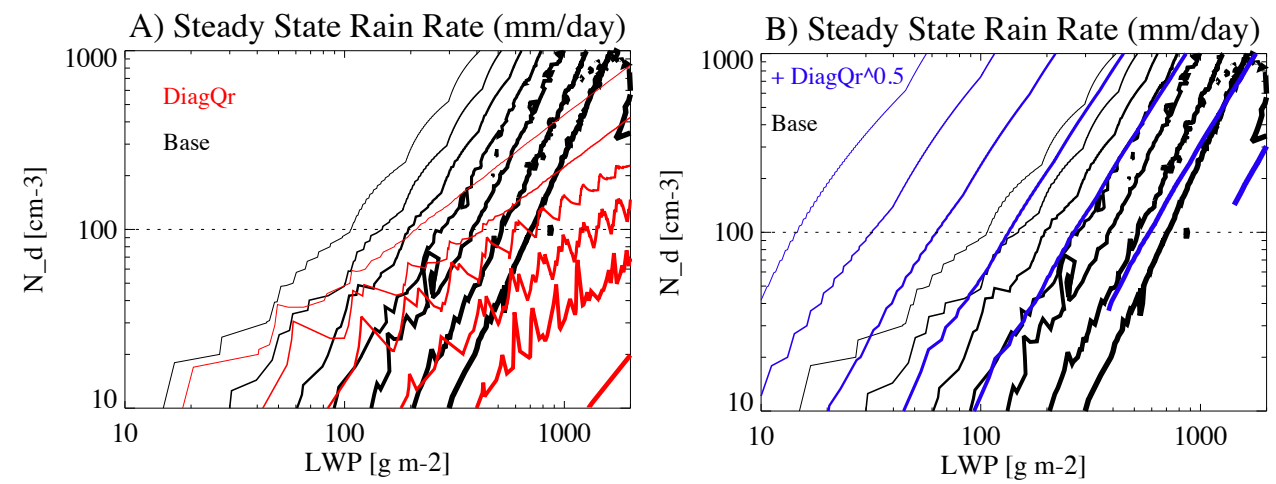

Fig. 2. Results from steady-state model of Wood et al. (2009). Rain rate (mm day ${ }^{-1}$ ), contour lines at $0.03,0.1,0.3,1,3,10$ and $30 \mathrm{~mm}$ $\mathrm{day}^{-1}$. Thicker lines are higher rain rates. Cases shown: (A) base case (Black) and Diagnostic rain case (DiagQr, Red). (B) Base case (Black) and diagnostic rain with vertical variation of rain rate from autoconversion (DiagQr ${ }^{0.5}$ : Blue) as described in the text.

Table 1. Description of steady-state simulations.

\begin{tabular}{ll}
\hline Name & Description \\
\hline Base & Base simulation \\
Qcv=2 & Modify rates with CAM sub-grid variability \\
DiagQr & Different accretion: with auto converted liquid \\
DiagQr ${ }^{0.5}$ & DiagQr + Scaled rain mixing ratio for accretion \\
\hline
\end{tabular}

ing a relative variance (variance divided by the mean incloud cloud water-mass mixing ratio), and analytically adjusting the process rates by integrating over an assumed gamma distribution. The result, for an inverse relative variance of 2 , is an increase in autoconversion by a factor of 2.02 , and of accretion by 1.04. It is straightforward to apply these terms to the steady-state model (simulation $\mathrm{Qcv}=2$ ), but the results do not change much. The precipitation rate is very similar to the base case (not shown) and the ratios between accretion and autoconversion (Fig. 3a), autoconversion and rain rate (Fig. $3 \mathrm{~b}$ ) and accretion and rain rate (Fig. 3c) are basically unchanged. The points in Fig. 3a-c are individual simulations. The linear arrangement of the points are from simulations with variable drop number for a fixed cloud height. As drop number increases, autoconversion decreases relative to accretion as expected. The "susceptibility" of precipitation to drop number (Fig. 3d), here defined as $S_{\mathrm{p}}=-\partial \ln (R) / \partial \ln \left(N_{\mathrm{d}}\right)$ with $R$ being the rain rate, is also very similar, with slightly lower values at high LWP for case Qcv=2.

\subsection{Modified accretion}

In addition, the GCM does not have rain mass and number mixing ratios that are carried from time step to time step (prognostic rain), but assumes instead that rain only depends on the prognostic cloud quantities over the model time step (typically $20-30 \mathrm{~min}$ ). Thus, rain profiles are found by in- tegration of the microphysical process rates over height but not time (diagnostic rain) as described in Morrison and Gettelman (2008), Sect. 2b. In the steady-state model, however, rain mass mixing ratios increase during spin up to steadystate at a given vertical level, leading to an increase in accretion. In the GCM, accretion is caused only by rain which is created (through autoconversion) diagnostically at each time step and falls through cloud water at lower levels. In order to reflect this behavior in the steady-state model, we can assume that accretion is affected only through rain created at the current time step, thus:

$\frac{\partial q_{\mathrm{r}}}{\partial t}{ }_{\text {accr }}=A_{\mathrm{c}}=67\left(q_{\mathrm{c}} q_{\mathrm{a}}\right)^{1.15}$,

where $q_{\mathrm{a}}$ is the "autoconverted" liquid $\left(q_{\mathrm{a}}\right)$ from the autoconversion rate $\left(q_{\mathrm{a}}=A_{\mathrm{u}} \rho \mathrm{d} t\right)$. This is a gross simplification of what the GCM does. The GCM uses a time independent balance between generation and sedimentation to estimate rain mass mixing ratio and hence accretion rate using two iterations The small time steps here make the generation term small, and so there is a danger of a regime shift in the rates at long GCM time steps. We test this effect below. This formulation (in red in Fig. 2 and Fig. 3) changes the balance dramatically in the steady-state model, causing a significant reduction in rain rate, and a constant relationship between the autoconversion and rain rate across all values of LWP (Fig. 3b). The accretion is much less important (Fig. 3c), and susceptibility to drop number (Fig. 3d) is increased at high LWPs (it does not decrease as in the standard steady-state model). This is consistent with previous work (Posselt and Lohmann, 2008; Wang et al., 2012) indicating that the prognostic rain formulation reduces the impact of autoconversion. Note that $q_{\mathrm{a}}$ in Eq. (3) is dependent on time step. We have tested a range of time steps from 5-30 s in the steady-state model. The value of the ratio does change with time step, but the time step does not change the susceptibility with LWP or the slope of the $A_{\mathrm{c}} / A_{\mathrm{u}}$ ratio with LWP. 

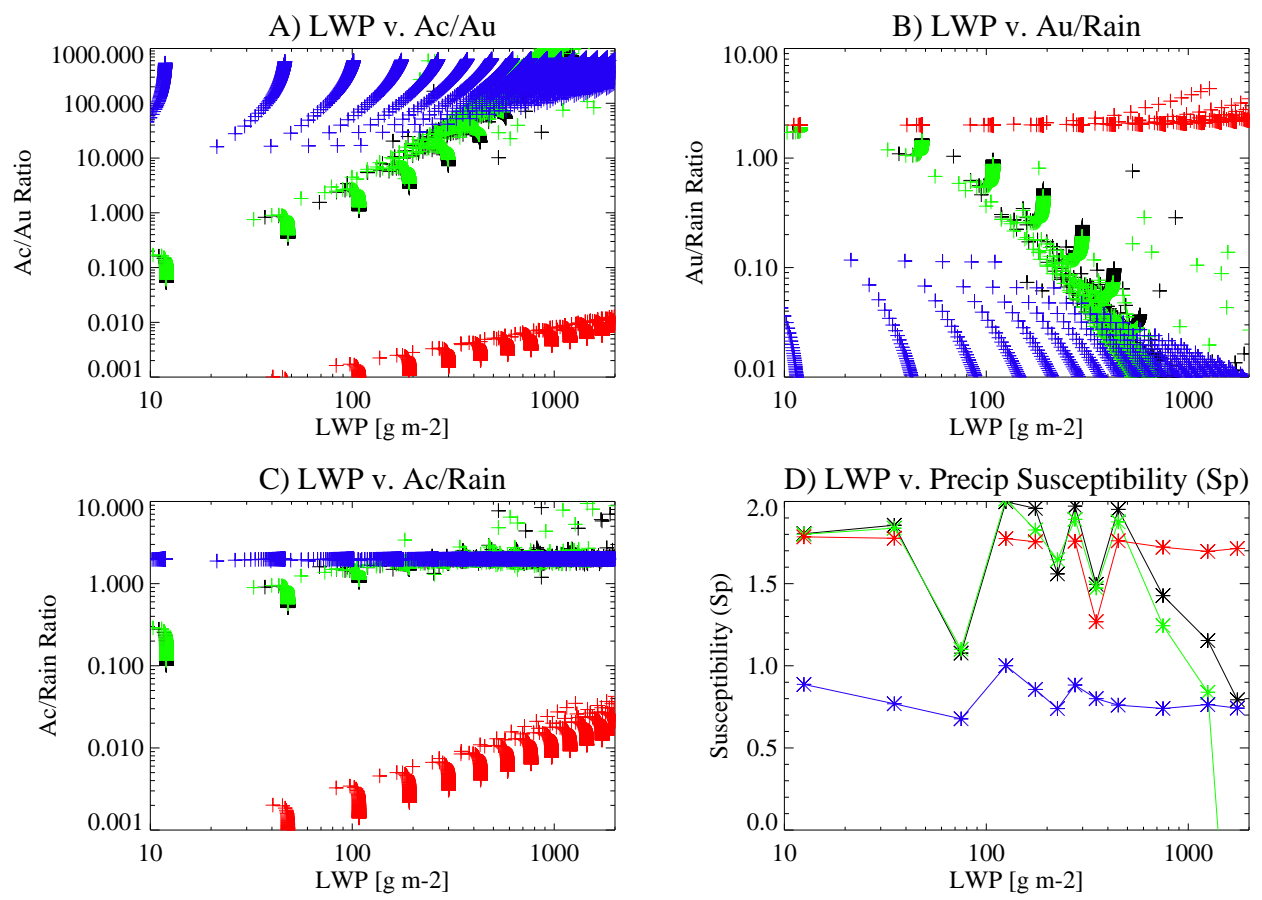

Fig. 3. Results from steady-state model of Wood et al. (2009). (A) LWP vs. accretion to autoconversion ratio ( $\left.A_{\mathrm{c}} / A_{\mathrm{u}}\right)$, (B) LWP vs. autoconversion to rain rate $\left(A_{\mathrm{u}} /\right.$ Rain), (C) LWP vs. the ratio of accretion to rain rate ( $A_{\mathrm{c}} /$ Rain) and (D) LWP vs. Precipitation Susceptibility. Cases shown: the base case (Black), case with sub-grid variability $(\mathrm{Qcv}=2)$ in green, diagnostic rain case (DiagQr, Red), and diagnostic rain with vertical variation of rain rate from autoconversion $\left(\mathrm{DiagQr}^{0.5}\right.$ : Blue) as described in the text.

Next we explore ways to recover the steady-state model behavior with the "diagnostic" rain rate (only from $q_{\mathrm{a}}$, the autoconverted liquid, as in Eq. 3). Boosting accretion by a factor of 10 alters the accretion/autoconversion $\left(A_{\mathrm{c}} / A_{\mathrm{u}}\right)$ ratio, but not significantly (experiments with this change look similar to the diagnostic rain in Fig. 3). As a second experiment, we assume that because $q_{\mathrm{r}}$ increases lower in the cloud, there is increased efficiency of accretion over autoconversion as the rain builds in the lower part of a cloud. We express this as a power law $q_{\mathrm{amod}}=q_{\mathrm{a}}^{x}$, where for $x<1$ accretion is boosted (since the rain mixing ratio $q_{\mathrm{r}}<1$ ). For illustrative purposes, we choose $x=0.5$ in Fig. 3 (DiagQr ${ }^{0.5}$ : blue lines). This method significantly increases the rain rate, matching the steady-state model base case for moderate LWP (100-300 $\left.\mathrm{g} \mathrm{m}^{-2}\right)$ in Fig. 2b. It also increases the accretion/autoconversion ratio (Fig. 3a) and the role of accretion in rain formation (Fig. 3c), and reduces the impact of autoconversion (Fig. 3b), while also uniformly lowering susceptibility (Fig. 3d). The results do not fully reproduce the base case steady-state model, particularly susceptibility $\left(S_{\mathrm{p}}\right)$ with respect to varying LWP. In Fig. 3d, for the simulations that give the two extremes of $A_{\mathrm{c}} / A_{\mathrm{u}}$ ratios (DiagQr ${ }^{0.5}$ in blue and DiagQr in red), $S_{\mathrm{p}}$ is nearly constant with LWP. Note that the susceptibilities in the steady-state model correspond to the exponents for autoconversion $(\sim 1.79)$ for all simulations except DiagQr ${ }^{0.5}$, where $S_{\mathrm{p}}$ is around half that of autoconver- sion $(\sim 0.9)$. In the steady-state model, the slope of the rain rate with specified droplet number is dominated by the exponent for autoconversion, but slightly less so when accretion dominates. Results are consistent with previous studies that susceptibility is related to the ratio between accretion and autoconversion. The similar slopes of Fig. 3b and Fig. 3d with LWP are consistent with previous work (Wang et al., 2012).

Steady-state model results indicate that altering the relation between microphysical sources and sinks can fundamentally alter the susceptibility of rain formation to drop number. Now we will explore these effects in the full GCM.

\section{GCM results}

We now focus on these process rates in the GCM, analyzing the ratio of accretion to autoconversion (Jiang et al., 2010), the ratio of autoconversion (and accretion) to precipitation (Wang et al., 2012), and the susceptibility of precipitation to aerosols (or drop number) (Sorooshian et al., 2009; Terai et al., 2012). We composite the diagnostics by LWP and by aerosol optical depth (AOD). Note that the LWP is that used in estimating microphysical process rates immediately before the microphysics calculation, not the diagnostic LWP in CAM used by the radiation code (the latter is the traditional GCM output). 

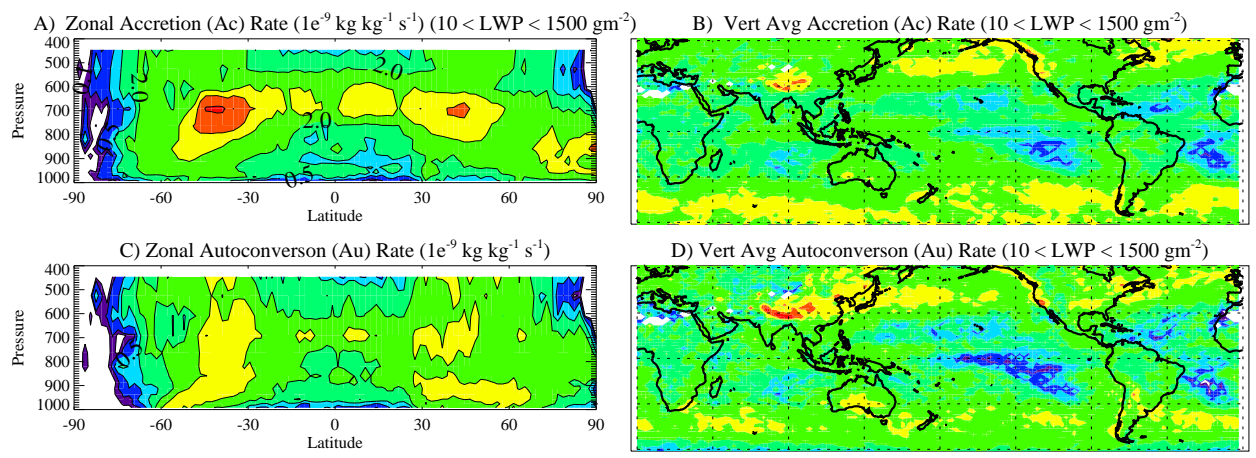

D) Vert Avg Autoconverson (Au) Rate $\left(10<\mathrm{LWP}<1500 \mathrm{gm}^{-2}\right)$
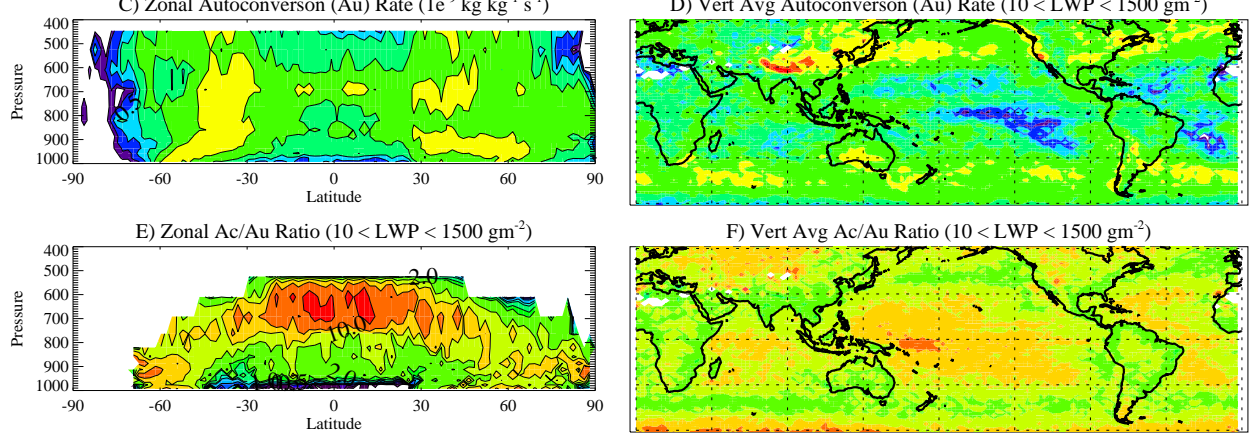

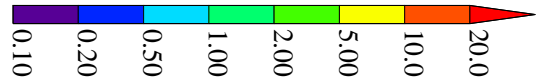

Ac, Au Process Rates $\left(1 \mathrm{e}^{-9} \mathrm{~kg} \mathrm{~kg}^{-1} \mathrm{~s}^{-1}\right)$

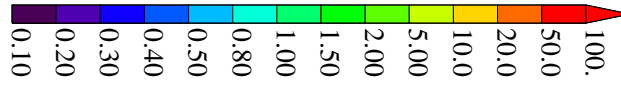

Ac/Au Ratio

Fig. 4. Zonal mean latitude height $(\mathbf{A}, \mathbf{C}, \mathbf{E})$ and vertically averaged maps $(\mathbf{B}, \mathbf{D}, \mathbf{F})$ of accretion rate $\left(A_{\mathrm{c}}\right.$ : $\left.\mathbf{A}, \mathbf{B}\right)$, autoconversion rate $\left(A_{\mathrm{u}}\right.$ : $\mathbf{C}$, D), and the ratio of accretion to autoconversion rate $\left(A_{\mathrm{c}} / A_{\mathrm{u}}: \mathbf{E}, \mathbf{F}\right)$ for all LWPs.

\subsection{Accretion/autoconversion}

The autoconversion of cloud condensate to precipitation and the accretion or collection of falling condensate by precipitation are the dominant terms in most places for the microphysical sink of cloud water (Fig. 1).

Figure 4 shows zonal cross sections and maps of the autoconversion and accretion rates in CAM5. As expected, autoconversion (Fig. 4d) and accretion (Fig. 4b) rates are both largest in mid-latitudes where stratiform LWPs are highest. Note that these processes and diagnostics do not treat convective clouds (because the simplified convective microphysics does not have these rates), so results for the tropics need to be interpreted with caution. The ratio between accretion and autoconversion (Fig. 4e) is large in the tropical troposphere below the melting level. This may result from rain formed by melting snow accreting liquid, but with limited liquid autoconversion. Because of the different vertical altitudes and sedimentation, and because it is the vertical integral that is relevant for surface precipitation rate, the vertically averaged $A_{\mathrm{c}}$ and $A_{\mathrm{u}}$ rates (over all altitudes, but essentially just the troposphere) are used for a ratio (Fig. 4f). In CAM5, accretion $\left(A_{\mathrm{c}}\right)$ dominates with the $A_{\mathrm{c}} / A_{\mathrm{u}}$ ratio typically between 1 and 10 , indicating that accretion is more important. The $A_{\mathrm{c}} / A_{\mathrm{u}}$ ratio is lower (more autoconversion) in the mid-latitude regions where the LWP is high.

In LES simulations (Jiang et al., 2010), the ratio of accretion to autoconversion increases with LWP in warm trade cumulus. Figure 5 shows an estimate of accretion and autoconversion rates based on observations. The autoconversion and accretion rates are estimated from the droplet size distributions measured on the NCAR/NSF C-130 during the VOCALS experiment off the west coast of South America on profile legs flown through the depth of the boundary layer (Wood et al., 2011). A mean droplet size distribution is calculated over ten second segments, and after interpolating any gaps in the size distribution, the mass conversion of cloud to drizzle for autoconversion and accretion is calculated using the stochastic collection equation given the size distribution following the method described by Wood (2005). The 10second-average process rates are averaged over continuous layers of liquid water content (LWC) exceeding $0.01 \mathrm{~g} \mathrm{~m}^{-3}$. The LWPs (drizzle+cloud) are estimated only over the cloud layer. A size (radius) cutoff of 25 microns is used to distinguish cloud and drizzle drops, following Khairoutdinov and Kogan (2000). Measurements of droplet size distribution come from the CDP (Cloud Droplet Probe) for the cloud drops and the 2D-C probe for drizzle drops (Wood et al., 2011). Here, the ratio of accretion to autoconversion increases sharply with LWP, as in the LES simulations of warm trade cumulus.

In CAM, the ratio of accretion to autoconversion $\left(A_{\mathrm{c}} / A_{\mathrm{u}}\right)$ decreases with LWP (Fig. 5a), in contrast to the observations and LES models. This appears to be mostly because autoconversion increases with LWP (Fig. 5b) faster than accretion (Fig. 5c). The $A_{\mathrm{c}} / A_{\mathrm{u}}$ ratio also decreases with 

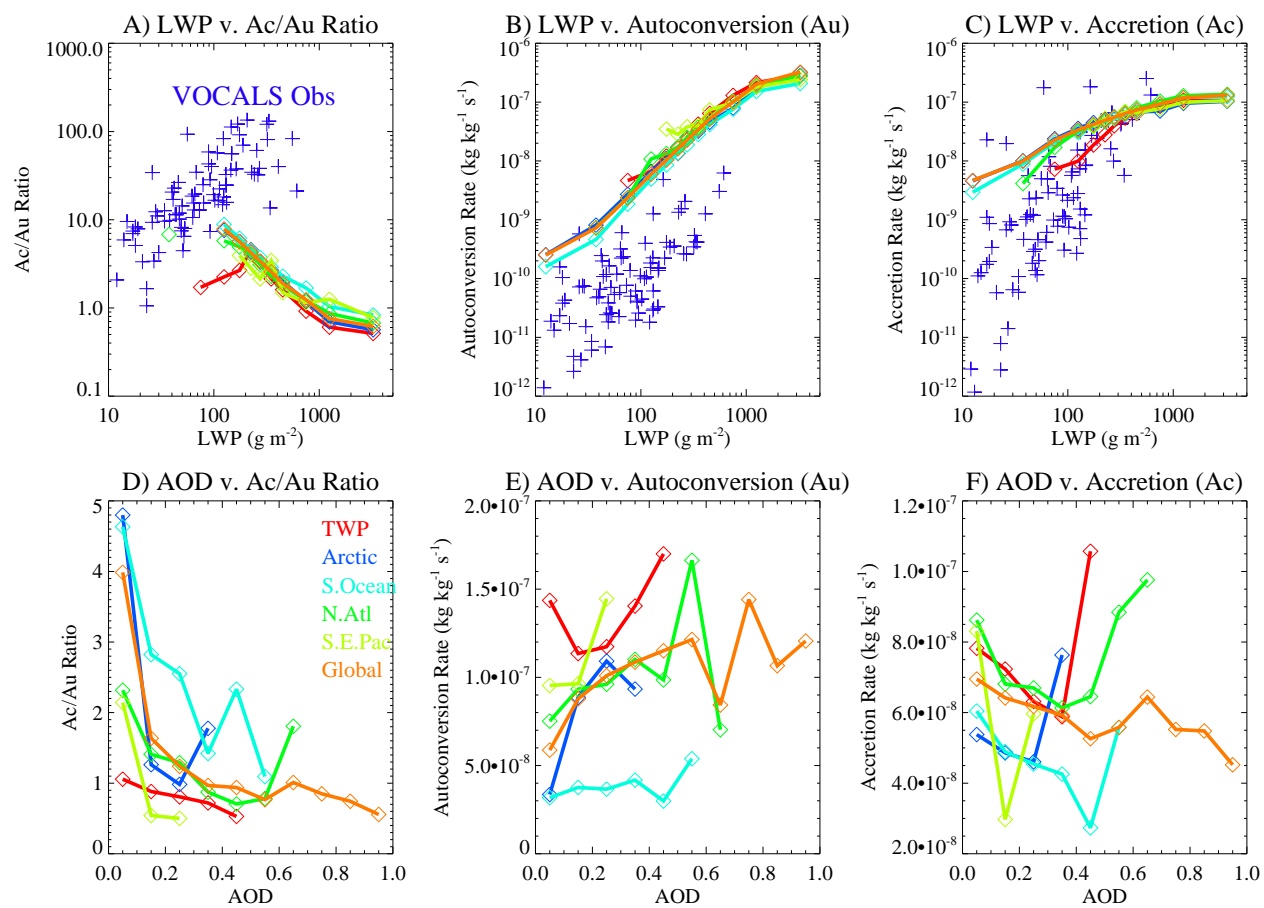

Fig. 5. GCM regional and global averages of vertically averaged (A) accretion/autoconversion $\left(A_{\mathrm{c}} / A_{\mathrm{u}}\right)$ ratio v. LWP, (B) autoconversion $\left(A_{\mathrm{u}}\right)$ rate v. LWP and $(\mathbf{C})$ accretion $\left(A_{\mathrm{c}}\right)$ rate v. LWP. Also shown are (D) $A_{\mathrm{c}} / A_{\mathrm{u}}$ ratio, $(\mathbf{E})\left(A_{\mathrm{u}}\right.$ and $(\mathbf{F}) A_{\mathrm{c}}$ v. AOD. Regions correspond to: tropical western Pacific (TWP: $\left.20^{\circ} \mathrm{S}-20^{\circ} \mathrm{N}, 120-160^{\circ} \mathrm{E}\right)$, Arctic $\left(65-80^{\circ} \mathrm{N}\right.$, all longitudes), Southern Ocean (65-60 $\mathrm{S}$, all longitudes), N. Atlantic $\left(40-60^{\circ} \mathrm{N}, 300-360^{\circ} \mathrm{E}\right)$, southeast Pacific $\left(30-10^{\circ} \mathrm{S}, 260-295^{\circ} \mathrm{E}\right)$, and global.

increasing AOD (Fig. 5d). Autoconversion increases with AOD in most regions (Fig.5e), which is not what would be expected from the formulation in Khairoutdinov and Kogan (2000) in Eq. (1). It may result from the fact that LWP increases with AOD in CAM, and the convolved variables make it difficult to separate AOD-driven effects in this analysis (the positive correlation between AOD and LWP does not imply causation, just covariance). Accretion decreases with AOD (Fig. 5f) globally. At high AOD some regions show increases in accretion. The relationships in Fig. 5d-f are valid if output is further stratified by LWP into high or low LWP cases only.

CAM has a fundamentally different relationship between the $A_{\mathrm{c}} / A_{\mathrm{u}}$ ratio and LWP than seen in the steady-state model in Fig. 3. The $A_{\mathrm{c}} / A_{\mathrm{u}}$ ratio increases with LWP (Fig. 3a) in the steady-state model or observationally based estimates in Fig. 5. However, in the steady-state model with modified accretion to reproduce the behavior in the GCM, following Eq. (3) (DiagQr), the $A_{\mathrm{c}} / A_{\mathrm{u}}$ ratio is 3 orders of magnitude lower than the basic steady-state model, and increases less with LWP.

\subsection{Precipitation and autoconversion}

To investigate the impact of microphysical processes and aerosols on precipitation, we look at the non-dimensional ra- tio of the vertical integral of autoconversion $\left(A_{\mathrm{u}}\right)$ or accretion $\left(A_{\mathrm{c}}\right)$ to the surface rain rate $(R)$ in Fig. 6. Previous studies (e.g., Wang et al., 2012) note that the autoconversion/rain ratio is important in determining LWP response to $\mathrm{CCN}$ because autoconversion is dependent on drop number. In drizzling stratocumulus, this ratio is small (Wood, 2005). Wang et al. (2012) highlight that the precipitation occurrence is related to the $A_{\mathrm{u}} / R$ ratio (since autoconversion is the initial formation of precipitation), whereas the precipitation amount is more dependent on the accretion process and the $A_{\mathrm{c}} / R$ ratio. Note that in CAM, there is an additional avenue for rain formation that is not accounted for in this analysis of autoconversion and accretion (for liquid): and that is the formation of frozen precipitation (snow) that melts to form rain. Hence there can be zero autoconversion or accretion for a non-zero rain rate in this analysis. This is not the case for warm shallow clouds (i.e., southeast Pacific), but this region is similar to others in the analysis.

In Fig. 6, the CAM $A_{\mathrm{u}} / R$ ratio increases with LWP, from 0.0 to 0.7 globally (Fig. 6a). There does not appear to be a clear relationship between the $A_{\mathrm{u}} / R$ ratio and AOD (Fig. 6c). The $A_{\mathrm{c}} / R$ ratio increases rapidly and then decreases with increasing LWP (Fig. 6b). These decreases are not seen in the steady-state model (Fig. $3 \mathrm{c}$ ). The $A_{\mathrm{c}} / R$ ratio decreases in many regions with higher AOD (Fig. 6d). The $A_{\mathrm{u}} / R$ and $A_{\mathrm{c}} / R$ ratios do not need to add up to one (i.e., $A_{\mathrm{c}}+A_{\mathrm{u}} \neq R$ ) 

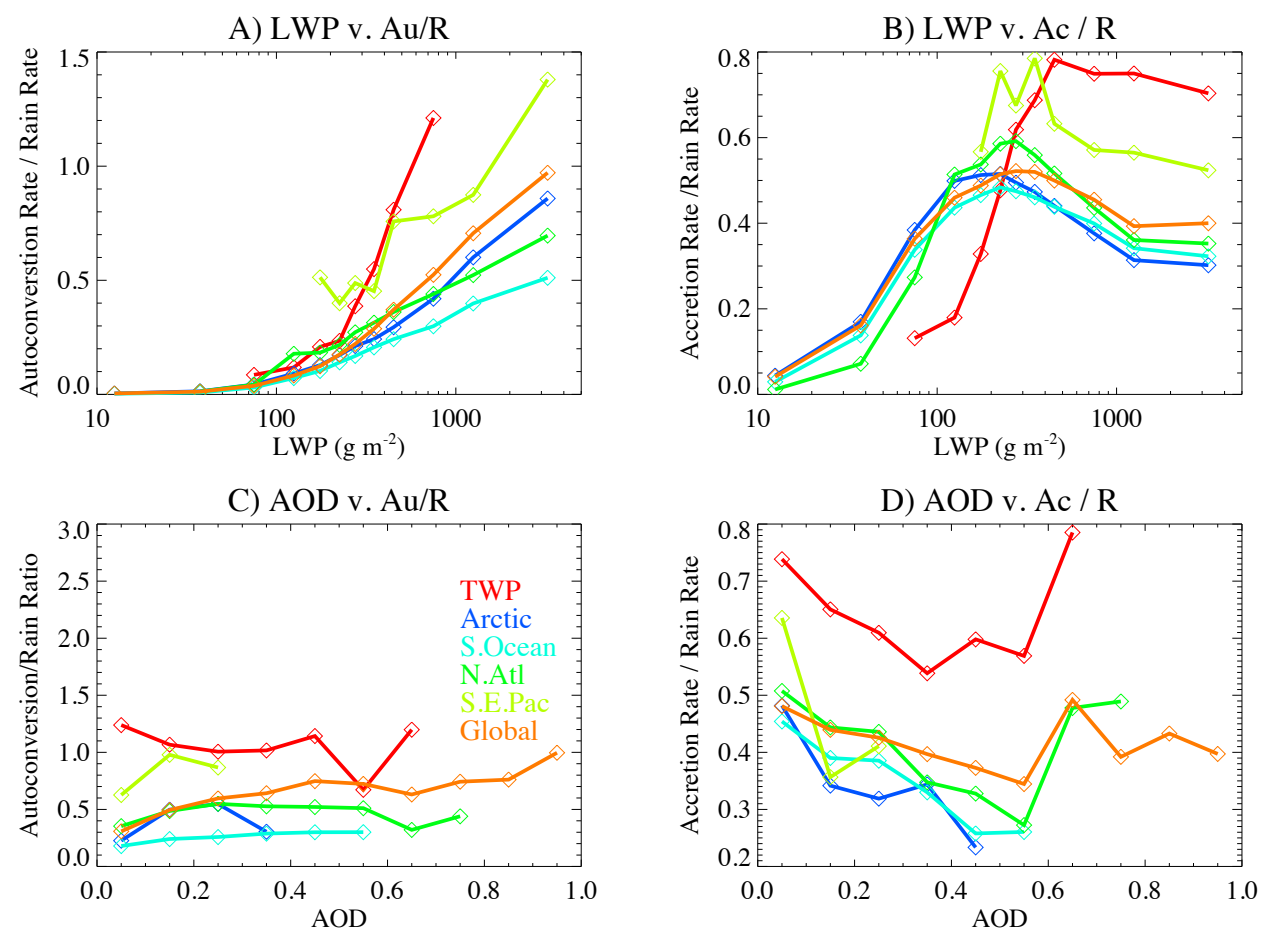

Fig. 6. Regional averages of the ratio of $(\mathbf{A}, \mathbf{C})$ autoconversion and $(\mathbf{B}, \mathbf{D})$ accretion to surface precipitation rate for different regions (colors, see Fig. 5 for description) binned by $(\mathbf{A}, \mathbf{B})$ LWP and $(\mathbf{C}, \mathbf{D})$ AOD.

because of the evaporation of precipitation (sum $>1$ ) or ice phase processes (sum $<1$ ). These ratios from CAM are consistent with other work (Wang et al., 2012). Autoconversion/rain ratios are much higher than seen in embedded cloud resolving model simulations by Wang et al. (2012), and in stratocumulus observations by Wood (2005), where autoconversion played a smaller part in determining rain rates. The $A_{\mathrm{u}} / R$ ratios (Fig. 6a) are very different from those in the steady-state model with prognostic rain (Fig. 3b, green and black), where the $A_{\mathrm{u}} / R$ ratio decreases with LWP. The GCM $A_{\mathrm{u}} / R$ ratio is more consistent with the increase in $A_{\mathrm{u}} / R$ ratio with LWP in steady-state model simulations using modified accretion (Fig. 3b, red).

\subsection{Precipitation susceptibility}

The susceptibility of precipitation $\left(S_{\mathrm{p}}\right)$ to aerosols is related to the cloud lifetime effect (Jiang et al., 2010; Feingold and Siebert, 2009). $S_{\mathrm{p}}$ is defined in the GCM similarly to the steady-state model, but using the column clouddrop number $(\mathrm{CDN})$ concentration for $N_{\mathrm{d}}$. Thus, $S_{\mathrm{p}}=$ $-\partial \ln (R) / \partial \ln (\mathrm{CDN})$. In the GCM, we look at instantaneous output from the model at each point, and consider only points with significant $\left(>2 \times 10^{-8} \mathrm{~m} \mathrm{~s}^{-1}\right.$, or $\left.1.8 \mathrm{~mm} \mathrm{day}^{-1}\right)$ rain rates in calculating the regression slope. The output is binned by region and LWP, and then slopes are calculated. In LES simulations of trade cumulus by Jiang et al. (2010), when binned by LWP, susceptibility increases with LWP, and then decreases at high LWP (> $1000 \mathrm{~g} \mathrm{~m}^{-2}$ ) as accretion dominates. In the LES model, this occurs because the precipitation process becomes more efficient but $N_{\mathrm{d}}$ increases suppress auto conversion. Terai et al. (2012) find only decreasing $S_{\mathrm{p}}$ with LWP in drizzling stratocumulus when non-drizzling profiles were included. Terai et al. (2012) found no change in $S_{\mathrm{p}}$ with LWP when only drizzling cases were examined. In the steady-state model (Fig. 3d), $S_{\mathrm{p}}$ is generally constant and then decreases for high LWP, but not for the two cases with altered accretion formulation (DiagQr and DiagQr ${ }^{0.5}$ ), where there is constant susceptibility at high LWP (Fig. 3d, red and blue).

We also investigated the use of the susceptibility to aerosol number of the probability of precipitation (POP), or $S_{\mathrm{POP}}=$ $-\partial \ln (\mathrm{POP}) / \partial \ln (\mathrm{AOD})$. This metric is thought to correlate with the $A_{\mathrm{u}} / R$ ratio (Wang et al., 2012). However, in application to the GCM, averaging is required in time and/or space to estimate POP, and this breaks the relationship between process rates and $S_{\mathrm{POP}}$. We have investigated these quantities in the GCM, using stratiform rain rates, and find results similar to Wang et al. (2012), but do not report them here since the focus is trying to relate to process rates.

Figure 7 indicates that in CAM5, precipitation susceptibility to drop number $\left(S_{\mathrm{p}}\right)$ increases with LWP up to LWP of several $100 \mathrm{~g} \mathrm{~m}^{-2}$ and then decreases in most regions, similar to $S_{\mathrm{p}}$ values reported by previous studies (Jiang et al., 2010; 


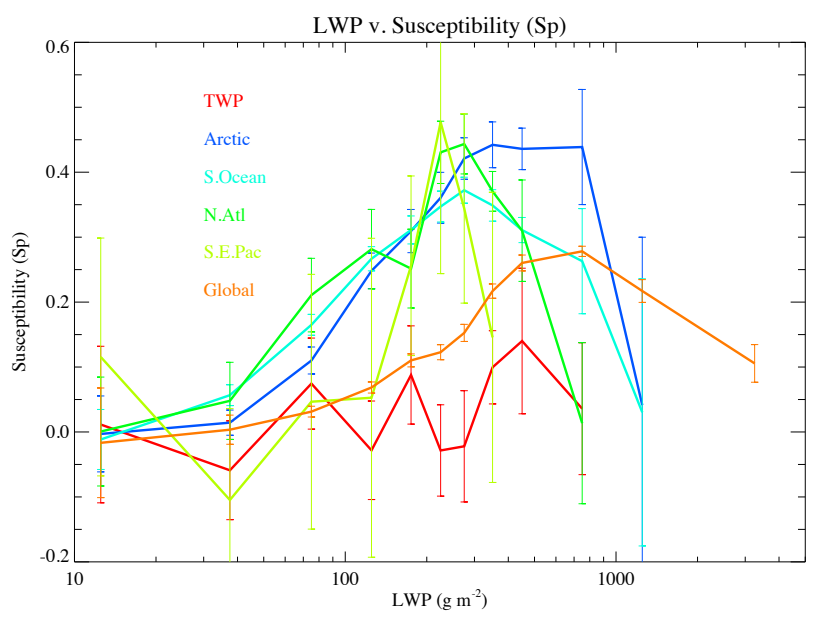

Fig. 7. Regional averages of precipitation susceptibility $\left(S_{\mathrm{p}}\right)$ as described in the text for different regions (colors, see Fig. 5 for description) binned by LWP.

Terai et al., 2012). Because of scatter, the quantitative values of $S_{\mathrm{p}}$ are lower than in the steady-state model (Fig. 3d). Terai et al. (2012) illustrate that adding scatter (noise) to the estimates of rain rate and cloud-drop number in log space tends to reduce the quantitative value of susceptibility. The high values of susceptibility at higher LWP are consistent with the results above showing a strong impact of autoconversion on rain rate at higher LWP (Fig. 6a). Since autoconversion depends on drop number, changes in drop number will have a large impact on autoconversion and hence rain rates. Note that there is little consistent change in $S_{\mathrm{p}}$ with LWP in the tropical western Pacific (TWP), but stratiform rain is small in this region (most is convective rain and not included in this analysis).

We have also looked at the ratio of the timescales for drizzle $\left(\tau_{\text {driz }}\right)$ and condensation ( $\left.\tau_{\text {cond }}\right)$ in the GCM. These are defined following Wood et al. (2009) as $\tau_{\text {driz }}=q_{1} /\left(A_{\mathrm{c}}+A_{\mathrm{u}}\right)$ and $\tau_{\text {cond }}=q_{1} / A_{\text {cond }}$ where $A_{\text {cond }}$ is the total condensation rate. Wood et al. (2009) found $\tau_{\text {driz }} / \tau_{\text {cond }}$ to be a good predictor of susceptibility $\left(S_{\mathrm{p}}\right)$. We do not see strong relationships between $\tau_{\text {driz }} / \tau_{\text {cond }}$ and $S_{\mathrm{p}}$. In general $\tau_{\text {driz }} / \tau_{\text {cond }}$ is low, and condensation dominates. Unlike the steady-state model, $\tau_{\text {driz }} / \tau_{\text {cond }}$ does not seem to determine the susceptibility $\left(S_{\mathrm{p}}\right)$ in the GCM.

\section{Global sensitivity tests and ACI}

\subsection{Simulation description}

We now examine how changes to the model formulation affect process rates and aerosol indirect effects. Sensitivity tests are listed in Table 2. Each test is a pair of simulations, run for five years at $1.9^{\circ} \times 2.5^{\circ}$ horizontal resolution with fixed year 2000 climatological sea surface temperatures
Table 2. Description of global simulations used in this study.

\begin{tabular}{|c|c|}
\hline Name & Description \\
\hline Base & Base simulation \\
\hline $\mathrm{Au} / 10$ & Autoconversion rate divided by $10 \times$ \\
\hline Ac $\cdot 10$ & Accretion rate increased by $10 \times$ \\
\hline $\mathrm{QrScl}^{0.75}$ & Scaled rain mixing ratio for accretion \\
\hline $\mathrm{d} T / 4$ & Physics time step reduced from 1800 to $450 \mathrm{~s}$ \\
\hline Base2 & Base simulation 2 (different code base) \\
\hline $\mathrm{AcAu} 2$ & $\mathrm{Ac} \cdot 10$ and $\mathrm{Au} / 10$ \\
\hline
\end{tabular}

(SSTs) and year 2000 greenhouse gas (GHG) concentrations. One simulation uses year 2000 aerosol emissions, and the other 1850 aerosol emissions. SSTs and GHGs are the same in both. We have thus far shown results from the year 2000 base simulation.

Aerosol emissions for either present day (2000) or "preindustrial" (1850) are from Lamarque et al. (2010). These are the same emissions used in the Coupled Model Intercomparison Project phase 5 (CMIP5) (Taylor et al., 2012). Total aerosol effects are estimated by looking at the radiative flux perturbation (RFP) in pairs of simulations with different aerosol emissions. The RFP is the change in top of atmosphere net radiative flux $(\mathrm{RFP}=d R$ ) including the longwave (LW) and shortwave (SW) components. CAM5.2 has a $\mathrm{SW}$ aerosol indirect effect of $-1.4 \mathrm{~W} \mathrm{~m}^{-2}$, mostly from liquid clouds, and a $\mathrm{LW}$ effect of $+0.4 \mathrm{~W} \mathrm{~m}^{-2}$, mostly from ice clouds (Table 3).

Based on the results of the steady-state model tests, we construct several different modifications to the microphysical process rates from the base model in Sect. 4. In one test, we reduce autoconversion by a factor of $10(\mathrm{Au} / 10)$. In another we increase accretion by a factor of 10 (Ac $\cdot 10)$, and in a third we scale the rain mixing ratio for accretion by an exponent of $0.75\left(\mathrm{QrScl}^{0.75}\right)$. The $\mathrm{QrScl}^{0.75}$ test is similar to the DiagQr ${ }^{0.5}$ steady-state model experiment. This experiment boosts accretion by using the scaled auto converted liquid instead of the diagnostic rain mixing ratio. In order to ensure that the level of liquid water in the simulated clouds does not decrease too much, we also scale back autoconversion in this test by a factor of 10 .

We also explore the impact of the coupling between condensation and microphysics in the simulations by reducing the time step by a factor of 4 from 1800 to $450 \mathrm{~s}$ (dT /4). The dynamics time step in the CAM5 finite volume core in standard $(\mathrm{d} T=1800 \mathrm{~s})$ simulations is sub-cycled 4 times, and this sub-stepping is set to 1 in the $\mathrm{d} T / 4$ simulations, so the dynamics has a similar effective time step, but the physics is running with a shorter time step (and affecting the dynamics more often). There are many couplings between the different physical processes that are altered in this simulation, so this is not a clean test for changing the microphysics time step. The intent is to try to reduce the amount of time for 
Table 3. Table of radiative property changes (year 2000-1850) from simulations. Illustrated are change in top of atmosphere radiative fluxes $(R)$, net cloud radiative effect (CRE) as well as the long-wave effect (LWE) and shortwave effect (SWE) components, the change in clear-sky shortwave radiation (FSC), ice water path (IWP) and year 2000 LWP. Also shown are changes to in-cloud ice number concentration (INC) and column liquid drop number $(\mathrm{CDN})$.

\begin{tabular}{lrrrrrrrrr}
\hline Run & $\begin{array}{r}d R \\
\mathrm{~W} \mathrm{~m}^{-2}\end{array}$ & $\begin{array}{r}d \mathrm{CRE} \\
\mathrm{W} \mathrm{m}^{-2}\end{array}$ & $\begin{array}{r}d \mathrm{LWE} \\
\mathrm{W} \mathrm{m}^{-2}\end{array}$ & $\begin{array}{r}d \mathrm{SWE} \\
\mathrm{W} \mathrm{m}^{-2}\end{array}$ & $\begin{array}{r}d \mathrm{FSC} \\
\mathrm{W} \mathrm{m}^{-2}\end{array}$ & $\begin{array}{r}\mathrm{LWP} \\
\mathrm{g} \mathrm{m}^{-2}\end{array}$ & $\begin{array}{r}d \mathrm{LWP} \\
\mathrm{g} \mathrm{m}^{-2}\end{array}$ & $\begin{array}{r}d \mathrm{INC} \\
\mathrm{L}^{-1}\end{array}$ & $\begin{array}{r}d \mathrm{CDN} \\
10^{10} \mathrm{~cm}^{-2}\end{array}$ \\
\hline Base & -1.40 & -1.06 & 0.48 & -1.54 & -0.46 & 44.0 & $3.1(7 \%)$ & $6.4(13 \%)$ & $0.62(40 \%)$ \\
$\mathrm{Au} / 10$ & -1.31 & -1.01 & 0.40 & -1.41 & -0.36 & 65.0 & $3.2(5 \%)$ & $5.9(12 \%)$ & $0.76(35 \%)$ \\
$\mathrm{Ac} \cdot 10$ & -1.37 & -1.22 & 0.70 & -1.92 & -0.34 & 28.1 & $2.7(10 \%)$ & $9.1(17 \%)$ & $0.41(48 \%)$ \\
$\mathrm{QrScl}^{0.75}$ & -1.18 & -1.00 & 0.68 & -1.68 & -0.35 & 31.2 & $1.4(5 \%)$ & $9.5(17 \%)$ & $0.42(41 \%)$ \\
$\mathrm{d} T / 4$ & -1.37 & -1.01 & 0.36 & -1.37 & -0.61 & 49.0 & $3.2(7 \%)$ & $7.8(8 \%)$ & $0.61(36 \%)$ \\
\hline Base2 & -1.55 & -1.25 & 0.43 & -1.68 & -0.32 & 44.4 & $3.2(7 \%)$ & $6.6(12 \%)$ & $0.64(41 \%)$ \\
AcAu2 & -1.21 & -1.10 & 0.61 & -1.71 & -0.25 & 44.4 & $2.4(5 \%)$ & $7.9(14 \%)$ & $0.55(35 \%)$ \\
\hline
\end{tabular}

microphysics to deplete the condensation which occurs. We also perform a test where $A_{\mathrm{c}}$ is increased (.10) and $A_{\mathrm{u}}$ lowered (/ 10) so that LWP is nearly constant (AcAu2). This test used a slightly different code (on a different supercomputer) so it is comparable only to its own base case (Base2). These cases are detailed in Table 2.

\subsection{Global results}

First we report basic statistics for the radiative impact of anthropogenic aerosols in the CAM5 simulations in Table 3. The quantitative radiative indirect effect (or ACI) can be isolated in several ways, following Gettelman et al. (2012). The change in cloud radiative effect $(d \mathrm{CRE})$ is representative of the indirect effect and can be broken into LW and SW components. CRE is the difference between the top of atmosphere flux for all sky and clear-sky conditions, for both shortwave (SWE) and long-wave (LWE). Alternatively, the change in clear-sky shortwave flux $(d \mathrm{FSC})$ is a measure of the direct scattering from aerosols, so the indirect effect (ACI) can also be RFP $-d$ FSC. In general these measures are similar.

Note that there are correlations between the change in shortwave cloud radiative effect ( $d$ SWE) and the mean LWP. An examination of differences in each simulation indicates that the magnitude of the ACI as defined by $d$ CRE scale roughly inversely with the mean LWP: the largest ACI (change in cloud radiative effect) occurs for the boosted accretion (Ac·10) simulation, which also has the smallest mean LWP, the largest change in LWP (Table 3), and the largest percent change in the cloud-drop number (CDN). Similar conclusions can be drawn from defining ACI = $d R-d \mathrm{FSC}$.

There is a fairly narrow $(\sim 25 \%)$ spread in ACI between simulations, despite large differences (a factor of 2) in mean LWP in Table 3. The consistency may be due to the buffering of processes coupling aerosols and clouds in the climate system (e.g., Stevens and Feingold, 2009). For exam- ple, cooling due to higher LWPs reduces surface evaporation and hence less moisture available in the atmosphere for cloud formation. The ACI defined by $d \mathrm{SWE}$ is correlated with the mean $\operatorname{LWP}\left(r^{2}=0.85\right)$ and $d \operatorname{LWP}\left(r^{2}=0.85\right)$. Platnick and Twomey (1994) note that low LWP clouds have higher albedo susceptibility $(\partial \ln [\alpha] / \partial \ln [\mathrm{CDN}])$, and similar radiative effects are seen here with global mean LWP (which also includes possible changes in cloud fraction): lower mean LWP results in higher SW effects. Cloud fraction does not change much between simulations, so most of the effects are for in-cloud LWP.

The LWP changes themselves are fairly easy to explain. Decreasing autoconversion $(\mathrm{Au} / \mathrm{10})$ increases mean presentday LWP substantially. Increasing accretion $(\mathrm{Ac} \cdot 10)$ decreases LWP. The QrScl test is a combination of increasing the accretion rate through scaling the rain mixing ratio (reducing LWP) and decreasing autoconversion to increase it again: the overall effect is to decrease LWP from the base case. The $\mathrm{d} T / 4$ case has $10 \%$ higher LWP than the base simulation: this is expected since a shorter time step means less time for large amounts of cloud water to build up after macrophysics but before microphysics, thus microphysical process rates (sinks) are smaller, explaining the increase in LWP. As shown by Golaz et al. (2011), these changes in LWP may affect ACI since changing $A_{\mathrm{u}}$ and $A_{\mathrm{c}}$ affect LWP as well as ACI. We control this by looking at an additional simulation: the AcAu2 simulation has the same mean LWP as its control, Base2 (Table 3). ACI in this simulation is $\sim 15 \%$ lower than Base2, indicating boosting accretion over autoconversion does have effects on ACI independent of mean LWP. Note that the change in LWP in AcAu2 is lower than Base2, so that the SW radiative ACI seems to be related to $d \mathrm{LWP}$.

Figure 8 illustrates the process rates in the different simulations. For increased accretion (Ac - 10) and scaled diagnostic rain $\left(\mathrm{QrScl}^{0.75}\right)$, the $A_{\mathrm{c}} / A_{\mathrm{u}}$ ratio is significantly reduced, and the slope with LWP is slightly reduced (Fig. 8a). This occurs because of a reduction in accretion and an increase in autoconversion, even if the accretion is boosted $\mathrm{Ac} \cdot 10$ and 

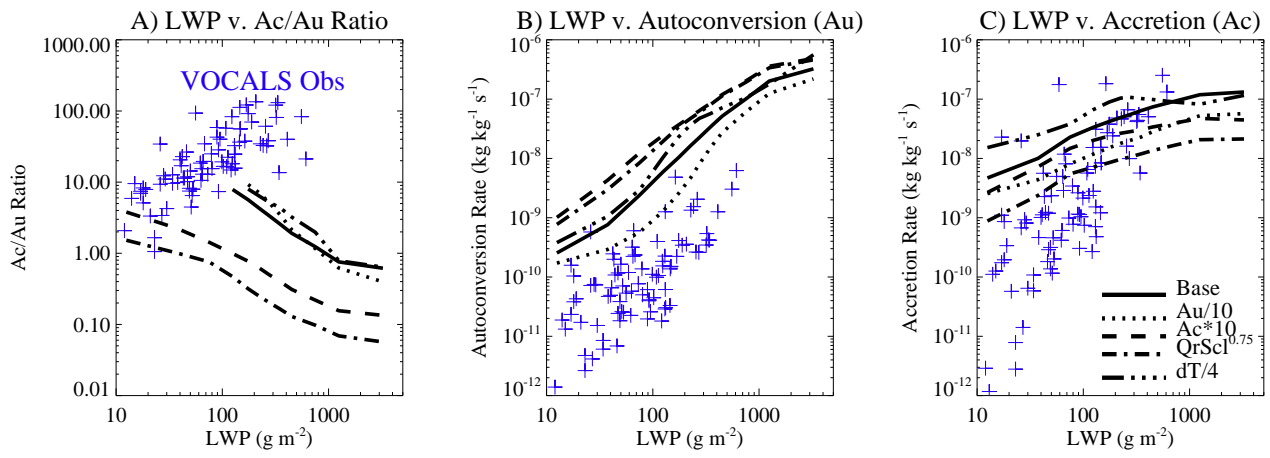

Fig. 8. Global averages of vertically averaged (A) accretion/autoconversion $\left(A_{\mathrm{c}} / A_{\mathrm{u}}\right)$ ratio v. LWP, (B) Autoconversion $\left(A_{\mathrm{u}}\right)$ rate v. LWP and (C) Accretion $\left(A_{\mathrm{c}}\right)$ rate v. LWP. Simulations are described in Table 2. Base CAM5 (solid), Au / 10 (dotted), Ac $\cdot 10$ : (dashed), QrScl ${ }^{0.75}$ (Dot Dashed) and dT /4 (triple dot-dash). Also shown are observational estimates (blue crosses) from VOCALS aircraft flights as described in the text.

$\mathrm{QrScl}^{0.75}$ ). Why does this antithetical behavior occur? The issue is probably because the output is viewed in LWP space. In the GCM, boosting accretion tends decrease LWP (shifting the curves to the left in Fig. 8a). The estimates based on VOCALS observations are also included in Fig. 8 (blue), and the behavior of the model is very different than the observations for all cases, as noted for the base case in Fig. 5.

There are significant changes in the precipitation susceptibility in the different simulations with altered process rates. Figure 9 illustrates the susceptibility for different simulations. The CAM5 base simulation (solid) features increasing susceptibility up to an LWP of about $800 \mathrm{~g} \mathrm{~m}^{-2}$. The reduced autoconversion $(\mathrm{Au} / 10)$ case has increased susceptibility to slightly higher LWPs. However, for the increased accretion cases (Ac-10 and $\mathrm{QrScl}^{0.75}$ ), with lower slope to the accretion/autoconversion ratio with LWP (Fig. 8a), the susceptibility is reduced significantly and approaches zero for higher LWPs. The simulation with smaller time step only $(\mathrm{d} T / 4)$ features the strongest increase in susceptibility. The changes in susceptibility in each region shown in Fig. 7 are similar to the global results in Fig. 9: $d T / 4$ has largest susceptibility and change, $\mathrm{Au} / 10$ and $\mathrm{QrScl}^{0.75}$ have lower sensitivity than the base case (not shown). The $A_{\mathrm{u}} / R$ ratio in these simulations (not shown) does not appear to predict the precipitation susceptibility $\left(S_{\mathrm{p}}\right)$, in contrast to the steady-state model (Fig. $3 b$ and d).

In the GCM, the susceptibility does not correlate with the $A_{\mathrm{c}} / A_{\mathrm{u}}$ ratio as strongly as in the steady-state model (when comparing DiagQr and DiagQr ${ }^{0.5}$ in Fig. 3). $S_{\mathrm{p}}$ seems related to the slope of the $A_{\mathrm{c}} / A_{\mathrm{u}}$ ratio (Fig. 8). $\mathrm{QrScl}^{0.75}$ and Ac $\cdot 10$ cases have lower LWP and lower $A_{\mathrm{c}} / A_{\mathrm{u}}$ ratio, but reduced $S_{\mathrm{p}}$ at high LWP. Note that this might be related to the LWP: in the steady-state model base case in Fig. 3, the $A_{\mathrm{c}} / A_{\mathrm{u}}$ ratio of the base case increases substantially, but susceptibility does not really respond until at around LWP $\sim 500$ $\mathrm{g} \mathrm{m}^{-2}$. This highlights the complexity of the interactions in the GCM, where multiple processes are affecting LWP in

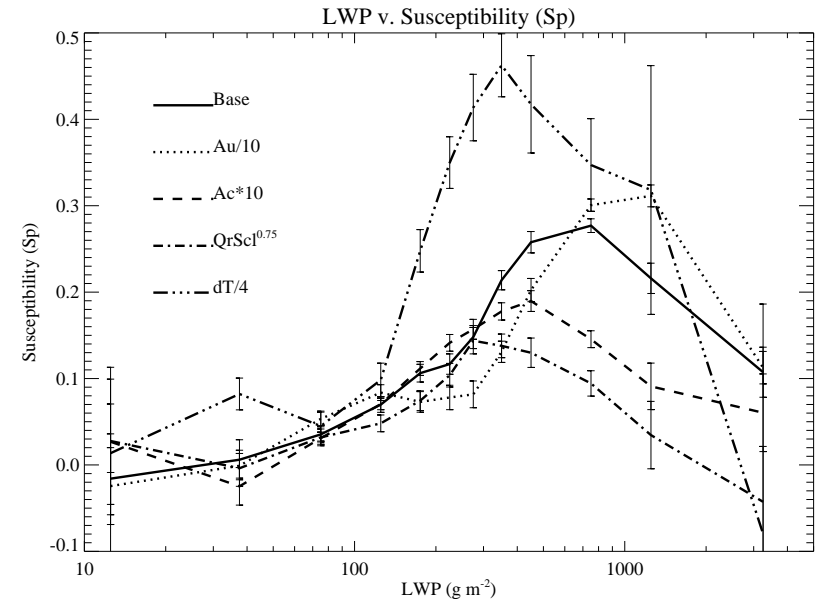

Fig. 9. Global average precipitation susceptibility $\left(S_{\mathrm{p}}\right)$ as defined in the text. Simulations are described in Table 2. Base CAM5 (solid), $\mathrm{Au} / 10$ (dotted), Ac·10: (dashed), $\mathrm{QrScl}^{0.75}$ (Dot Dashed) and $\mathrm{d} T / 4$ (triple dot-dash)

multiple regimes. There are also ice processes in many GCM regions that complicate the analysis.

\section{Discussion/conclusions}

Autoconversion and accretion processes modulate the LWP with bulk 2 moment microphysics in the GCM. This is seen in microphysical budget calculations (Fig. 1) as well as in sensitivity tests, where altering these process rates has direct impacts on LWP (Table 3). The mean state of the GCM climate (base LWP) is quite sensitive to the formulation of the microphysical process rates: accretion and autoconversion have direct impacts on sources and sinks of liquid. The coupling of these processes to the rest of the model, by altering the time step, also impacts the mean state. These results 
are consistent with previous work, but use analysis of observations and a steady-state model.

We conclude that the simple steady-state model reproduces many of the features seen in cloud resolving (LES) models and observations. The steady-state model can also be made to produce similar relationships as in the global model when used with modified accretion (DiagQr) to reflect diagnostic precipitation. It does not appear as if the bulk, semiempirical formulations of the process rates derived from fits to a CRM by Khairoutdinov and Kogan (2000) cause the relative increase in autoconversion over accretion with higher LWP, since this does not occur in the steady-state model with these same formulations. This is an important conclusion for many scales of modeling.

The behavior of the CAM5 GCM is similar to the steadystate model with the modified accretion formulation. In the GCM, autoconversion increases relative to accretion at higher LWPs (Fig. 5). The microphysical behavior seems fairly consistent across regions. The proportion of rain from autoconversion also increases as LWP increases (Fig. 6). Because autoconversion is dependent strongly on drop number, it links aerosols to cloud lifetime increases and the decrease in precipitation. Susceptibility increases with LWP in CAM up to large values of LWP (Fig. 7), and higher susceptibility is found in regions with higher LWP and lower $A_{\mathrm{c}} / A_{\mathrm{u}}$ ratios (Fig. 4f).

Posselt and Lohmann (2008) showed that diagnostic rain leads to overestimating the importance of autoconversion and Wang et al. (2012) showed that the $A_{\mathrm{u}} / R$ ratio correlated with the sensitivity of LWP to aerosols. Here we illustrate that using a "diagnostic-like" formulation in the steady-state model can drastically shift the rain formation from accretion to autoconversion. Attempting to correct the GCM by boosting accretion (as in $\mathrm{Ac} \cdot 10$ or $\mathrm{QrScl}^{0.75}$ ), the GCM still has a difficult time capturing the expected behavior of the $A_{\mathrm{c}} / A_{\mathrm{u}}$ ratio. This might result from long time steps for microphysical process rates in the GCM, where limiters are applied to limit process rates to the available water, changing the process rate relationships from their theoretical value. While the tendency for increasing autoconversion with LWP is still present in the GCM, susceptibility does appear to be reduced when the process rates are modified (Fig. 9) to increase accretion.

Radiative ACI in the GCM may be sensitive to the formulation of the diagnostic precipitation. CAM5 is conceptually similar to many other GCMs in how it treats cloud microphysics and aerosols, so these results might be generally applicable across models. Possible sensitivities to LWP complicate this interpretation, consistent with radiative effects (Platnick and Twomey, 1994) and recent GCM tuning simulations (Golaz et al., 2011). ACI is higher for lower mean LWP and larger percent changes in LWP. Reductions of ACI of $20 \%$ or so, and decreases in precipitation susceptibility (Fig. 9) result from these process rate changes, mostly from reducing autoconversion or boosting accretion.
These conclusions will need further testing in both GCM and off-line frameworks, including in other GCMs. The possibility also exists that the numerics may have an impact. The combination of the diagnostic precipitation assumption with relatively long time steps (20 min, with $10 \mathrm{~min}$ iterations for precipitation), as well as coarse vertical grid spacing (500$1000 \mathrm{~m}$ in the free troposphere) may impact the simulations by imposition of limiters that break the relationships diagnosed in the steady-state model. To address this we are focusing future work on the numerical implementation of microphysics in GCMs.

Acknowledgements. Computing resources were provided by the Climate Simulation Laboratory at National Center for Atmospheric Research (NCAR) Computational and Information Systems Laboratory. NCAR is sponsored by the U.S. National Science Foundation (NSF). The authors were supported by a Climate Process Team grant from NSF, AGS-0968657.

Edited by: B. Albrecht

\section{References}

Ackerman, A. S., Kirkpatrick, M. P., Stevens, D. E., and Toon, O. B.: The impact of humidity above stratiform clouds on indirect aerosol climate forcing, Nature, 432, 1014-1017, 2004.

Albrecht, B. A.: Aerosols, cloud microphysics and fractional cloudiness, Science, 245, 1227-1230, 1989.

Boucher, O. and Lohmann, U.: The sulfate-CCN-cloud albedo effect. A sensitivity study with two general circulation models, Tellus, 47B, 281-300, 1995.

Feingold, G. and Siebert, H.: Cloud-Aerosol Interactions from the Micro to the Cloud Scale, in: Clouds in the Perturbed Climate System, edited by Heintzenberg, J. and Charlson, R. J., MIT Press, 2009.

Gettelman, A., Morrison, H., and Ghan, S. J.: A new two-moment bulk stratiform cloud microphysics scheme in the NCAR Community Atmosphere Model (CAM3), Part II: Single-Column and Global Results, J. Clim., 21, 3660-3679, 2008.

Gettelman, A., Liu, X., Ghan, S. J., Morrison, H., Park, S., Conley, A. J., Klein, S., Boyle, J., Mitchell, D. L., and Li, J.-L. F.: Global Simulations of Ice nucleation and Ice Supersaturation with an Improved Cloud Scheme in the Community Atmosphere Model, J. Geophys. Res., 115, D18216, doi:10.1029/2009JD013797, 2010.

Gettelman, A., Kay, J. E., and Shell, K. M.: The Evolution of Climate Feedbacks in the Community Atmosphere Model, J. Clim., 25, 1453-1469, doi:10.1175/JCLI-D-11-00197.1, 2012.

Golaz, J.-C., Saltzmann, M., Donner, L. J., Horowitz, L. W., Ming, Y., and Zhao, M.: Sensitivity of the aerosol indirect effect to subgrid variability in the cloud parameterization of the GFDL Atmosphere General Circulation Model AM3, J. Clim., 24, 31453160, doi:10.1175/2010JCLI3945.1, 2011.

Guo, H., Golaz, J.-C., and Donner, L. J.: Aerosol effects on stratocumulus water paths in a PDF-based parameterization, Geophys. Res. Lett., 38, L17808, doi:10.1029/2011GL048611, 2011. 
Jiang, H., Feingold, G., and Sorooshian, A.: Effect of Aerosol on the Susceptibility and Efficiency of Precipitation in Warm Trade Cumulus Clouds, J. Atmos. Sci., 67, 3526-3540, 2010.

Khairoutdinov, M. F. and Kogan, Y.: A new cloud physics parameterization in a large-eddy simulation model of marine stratocumulus, Mon. Weather Rev., 128, 229-243, 2000.

Lamarque, J.-F., Bond, T. C., Eyring, V., Granier, C., Heil, A., Klimont, Z., Lee, D., Liousse, C., Mieville, A., Owen, B., Schultz, M. G., Shindell, D., Smith, S. J., Stehfest, E., Van Aardenne, J., Cooper, O. R., Kainuma, M., Mahowald, N., McConnell, J. R., Naik, V., Riahi, K., and van Vuuren, D. P.: Historical (1850-2000) gridded anthropogenic and biomass burning emissions of reactive gases and aerosols: methodology and application, Atmos. Chem. Phys., 10, 7017-7039, doi:10.5194/acp10-7017-2010, 2010.

Liu, X., Easter, R. C., Ghan, S. J., Zaveri, R., Rasch, P., Shi, X., Lamarque, J.-F., Gettelman, A., Morrison, H., Vitt, F., Conley, A., Park, S., Neale, R., Hannay, C., Ekman, A. M. L., Hess, P., Mahowald, N., Collins, W., Iacono, M. J., Bretherton, C. S., Flanner, M. G., and Mitchell, D.: Toward a minimal representation of aerosols in climate models: description and evaluation in the Community Atmosphere Model CAM5, Geosci. Model Dev., 5, 709-739, doi:10.5194/gmd-5-709-2012, 2012.

Martin, G. M., Johnson, D. W., and Spice, A.: The measurement and parameterization of effective radius of droplets in warm stratocumulus clouds, J. Atmos. Sci., 51, 1823-1842, 1994.

Morrison, H. and Gettelman, A.: A new two-moment bulk stratiform cloud microphysics scheme in the NCAR Community Atmosphere Model (CAM3), Part I: Description and Numerical Tests, J. Clim., 21, 3642-3659, 2008.

Murphy, D. M., Solomon, S., Portmann, R. W., Rosenlof, K. H., Forster, P. M., and Wong, T.: An observationally based energy balance for the Earth since 1950, J. Geophys. Res., 114, doi:10.1029/2009JD012105, 2009.

Neale, R. B., Chen, C. C., Gettelman, A., Lauritzen, P. H., Park, S., Williamson, D. L., Conley, A. J., Garcia, R., Kinnison, D., Lamarque, J. F., Marsh, D., Mills, M., Smith, A. K., Tilmes, S., Vitt, F., Cameron-Smith, P., Collins, W. D., Iacono, M. J., Easter, R. C., Ghan, S. J., Liu, X., Rasch, P. J., and Taylor, M. A.: Description of the NCAR Community Atmosphere Model (CAM5.0), Tech. Rep. NCAR/TN-486+STR, National Center for Atmospheric Research, Boulder, CO, USA, 2010.

Penner, J., Xu, L., and Wang, M.: Satellite methods underestimate indirect climate forcing by aerosols, Proc. Nat. Acad. Sci., 108, 12404-13408, 2011.

Platnick, S. and Twomey, S.: Determining the susceptibility of cloud albedo to changes in droplet concentration with the Advanced Very High Resolution Radiometer, J. Applied Met., 33, 334-347, 1994.

Posselt, R. and Lohmann, U.: Introduction of prognostic rain in ECHAM5: design and single column model simulations, Atmos. Chem. Phys., 8, 2949-2963, doi:10.5194/acp-8-2949-2008, 2008.

Quaas, J., Boucher, O., Bellouin, N., and Kinne, S.: Satellite-based estimate of the direct and indirect aerosol climate forcing, J. Geophys. Res., 113, D05204, doi:10.1029/2007JD008962, 2008.
Ramanathan, V., Crutzen, P. J., Kiehl, J. T., and Rosenfeld, D.: Aerosols, climate and the hydrologic cycle, Science, 294, 21192124, 2001.

Rosenfeld, D., Lohmann, U., Raga, G. B., O’Dowd, C. D., Kulmala, M., Fuzzi, S., Reissell, A., and Andreae, M. O.: Flood or Drought: How do Aerosols Affect Precipitation, Science, 321, 1309-1313, 2008.

Sorooshian, A., Feingold, G., Lebsock, M. D., Jiang, H., and Stephens, G. L.: On the precipitation susceptibility of clouds to aerosol perturbations, Geophys. Res. Lett., 36, L13803, doi:10.1029/2009GL038993, 2009.

Stevens, B. and Feingold, G.: Untangling aerosol effects on clouds and precipitation in a buffered system, Nature, 461, 607-613, 2009.

Stevens, B. and Seifert, A.: Understanding microphysical outcomes of microphysical choices in simulations of shallow cumulus convection, J. Meteor. Soc. Japan, 86, 143-162, 2008.

Taylor, K. E., Stouffer, R. J., and Meehl, G. A.: An Overview of CMIP5 and the Experimental Design, B. Am. Meteorol. Soc, 93, 485-498, doi:10.1175/BAMS-D-11-00094.1, 2012.

Terai, C. R., Wood, R., Leon, D. C., and Zuidema, P.: Does precipitation susceptibility vary with increasing cloud thickness in marine stratocumulus?, Atmos. Chem. Phys., 12, 4567-4583, doi:10.5194/acp-12-4567-2012, 2012.

Twomey, S.: The Influence of Pollution on the Shortwave Albedo of Clouds, J. Atmos. Sci., 34, 1149-1152, 1977.

Wang, M., Ghan, S., Liu, X., L'Ecuyer, T. S., Zhang, K., Morrison, H., M. Ovchinnikov, R. E., Marchand, R., Chand, D., Qian, Y., and Penner, J. E.: Constraining cloud lifetime effects of aerosols using A-Train Satellite observations, Geophys. Res. Lett., 39, L15709, doi:10.1029/2012GL052204, 2012.

Wood, R.: Drizzle in stratiform boundary layer clouds. Part II: Microphysical aspects, J. Atmos. Sci., 62, 3034-3050, 2005.

Wood, R., Kubar, T. L., and Hartmann, D. L.: Understanding the Importantce of Microphysics and Macrophysics for Warm Rain in Marine Low Clouds. Part II: Heuristic Models of Rain Formation, J. Atmos. Sci., 66, 2973-2990, doi:10.1175/2009JAS3072.1, 2009.

Wood, R., Mechoso, C. R., Bretherton, C. S., Weller, R. A., Huebert, B., Straneo, F., Albrecht, B. A., Coe, H., Allen, G., Vaughan, G., Daum, P., Fairall, C., Chand, D., Gallardo Klenner, L., Garreaud, R., Grados, C., Covert, D. S., Bates, T. S., Krejci, R., Russell, L. M., de Szoeke, S., Brewer, A., Yuter, S. E., Springston, S. R., Chaigneau, A., Toniazzo, T., Minnis, P., Palikonda, R., Abel, S. J., Brown, W. O. J., Williams, S., Fochesatto, J., Brioude, J., and Bower, K. N.: The VAMOS Ocean-Cloud-AtmosphereLand Study Regional Experiment (VOCALS-REx): goals, platforms, and field operations, Atmos. Chem. Phys., 11, 627-654, doi:10.5194/acp-11-627-2011, 2011.

Zhang, G. J. and McFarlane, N. A.: Sensitivity of climate simulations to the parameterization of cumulus convection in the Canadian Climate Center general circulation model, Atmos. Ocean, 33, 407-446, 1995. 